\title{
HUBUNGAN LAMA DUDUK DENGAN KEJADIAN LOW BACK PAIN PADA OPERATOR KOMPUTER PERUSAHAAN TRAVEL DI MANADO
}

\author{
${ }^{1}$ Ni Putu L. N. I. Sari \\ ${ }^{2}$ Theresia Isye Mogi \\ ${ }^{2}$ Engeline Angliadi
}

\author{
${ }^{1}$ Kandidat Skripsi Fakultas Kedokteran Universitas Sam Ratulangi \\ ${ }^{2}$ Bagian Ilmu Kedokteran Fisik dan Rehabilitasi Universitas Sam Ratulangi Manado \\ Email: lilinurindahsari16@gmail.com
}

\begin{abstract}
Low Back Pain (LBP) is commonly found in society. LBP often results in decreased of productivity and disability. The most frequent causes of LBP are prolonged sitting, improper sitting position, bad body posture, excessive activity, and trauma. Risks of LBP are prolonged working such as computer operator. This study aimed to obtain the correlation of sitting duration of computer operators in travel agencies in Manado to LBP. This was an analytical observasional study with a cross sectional design. Data were collected by using questionnaires. The result showed that of 30 subjects, 27 (90\%) had suffered from LBP. An upright sitting position is the most position that caused LBP in 18 subjects (60\%). The sitting position where the knees were as high as the hip caused LBP in 25 subjects (83,33\%). Prolonged sitting of 7-8 hours contributed in 21 subjects (70\%). The alternative Fisher exact test showed a strong correlation $(\mathrm{P}=0.014)$ between prolonged sitting and LBP in computer operators of travel agencies. An upright sitting position $(\mathrm{P}=0.028)$ and the sitting position where knees were as high as the hips $(\mathrm{P}=0.003)$ were also correlated with LBP.
\end{abstract}

Keywords: low back pain, computer operator, sitting position, knee position

\begin{abstract}
Abstrak: Low Back pain (LBP) merupakan keluhan yang sering dijumpai dalam masyarakat. LBP sering menyebabkan penurunan produktivitas kerja juga disabilitas. Penyebab LBP yang paling sering ialah duduk terlalu lama, sikap duduk yang tidak tepat, postur tubuh yang tidak ideal, aktivitas berlebihan, serta trauma. Pekerjaan yang berisiko menimbulkan LBP antara lain yang memiliki jam kerja panjang seperti operator komputer. Penelitian ini bertujuan untuk mengetahui hubungan lama duduk dan angka kejadian LBP pada operator komputer perusahaan travel di Manado dengan menggunakan metode analitik observasional dan desain potong lintang. Data dikumpulkan menggunakan kuesioner kemudian dianalisis. Hasil penelitian memperlihatkan dari jumlah 30 subjek penelitian, 27 orang (90\%) mengalami LBP. Posisi duduk tegak merupakan posisi terbanyak yang menimbulkan LBP pada 18 subjek penelitian (60\%). Posisi lutut sejajar pinggul menimbulkan LBP pada 25 subjek penelitian (83,33\%). Lama duduk 7-8 jam paling banyak menimbulkan LBP yaitu pada 21 subjek penelitian (70\%). Uji alternatif Fisher exact memperlihatkan adanya korelasi kuat $(\mathrm{P}=0,014)$ antara lama duduk dan kejadian LBP pada operator komputer perusahaan travel. Posisi duduk tegak $(\mathrm{P}=0,028)$ dan posisi lutut sejajar pinggul $(\mathrm{P}=0,003)$ juga berkorelasi dengan LBP

Kata kunci: low back pain, lama duduk, operator komputer, posisi duduk, posisi lutut,
\end{abstract}

Low Back Pain (LBP) merupakan keluhan yang sering dijumpai dan umum dalam masyarakat. Hampir setiap orang pernah merasakan LBP dalam hidupnya. LBP termasuk salah satu gangguan muskuloskeletal yang sering terjadi dan menyebab- 
kan penurunan produktivitas kerja dan disabilitas. LBP memiliki dampak besar terhadap individu, keluarga, masyarakat dan bisnis di seluruh dunia. ${ }^{1}$

LBP didefinisikan sebagai suatu kondisi tidak spesifik yang mengacu pada keluhan nyeri akut atau kronik dan ketidaknyamanan pada atau di dekat daerah lumbosakral, yang dapat disebabkan oleh inflamasi, proses degeneratif, keganasan, kelainan ginekologi, trauma, dan gangguan metabolik. ${ }^{2}$

Data di RSUP Prof. Dr. R. D. Kandou Manado pada periode 1 Januari 2007 sampai dengan 31 Desember 2008 memperlihatkan jumlah penderita LBP sebanyak 203 (0,92\%) dari total 22.307 seluruh penderita penyakit saraf yang datang di Poliklinik Saraf RSUP Prof. Dr. R. D. Kandou Manado. ${ }^{3}$

Nyeri punggung tersebut dapat terjadi pada berbagai situasi kerja, tetapi risikonya lebih besar apabila duduk lama dalam posisi statis karena akan menyebabkan kontraksi otot yang terus menerus serta penyempitan pembuluh darah. Pada penyempitan pembuluh darah aliran darah terhambat dan terjadi iskemia, jaringan kekurangan oksigen dan nutrisi, sedangkan kontraksi otot yang lama akan menyebabkan penumpukan asam laktat; kedua hal tersebut menyebabkan nyeri. ${ }^{4}$

Beberapa kegiatan seperti jogging dan berjalan di jalan raya (bukan di area jogging) mengangkat benda berat dan lama duduk (terutama di mobil, truk dan kursi yang dirancang buruk) dapat memprovokasi nyeri punggung. ${ }^{5}$ Penyebab LBP yang paling sering ialah duduk terlalu lama, sikap duduk yang tidak tepat, postur tubuh yang tidak ideal, aktivitas yang berlebihan serta trauma. Nyeri punggung menjadi masalah di banyak negara karena seringkali memengaruhi produktivitas kerja. ${ }^{6}$

Pekerjaan yang berisiko menimbulkan LBP antara lain pekerjaan yang memiliki jam kerja panjang dan mengharuskan karyawannya untuk duduk dalam waktu yang lama pada posisi duduk tertentu, ${ }^{7}$ seperti operator komputer, penjahit, karyawan bank, dan pengemudi.
Penelitian ini bertujuan untuk mengetahui hubungan antara lama duduk dengan kejadian LBP pada operator komputer perusahaan travel di Manado.

\section{METODE PENELITIAN}

Penelitian dilakukan di beberapa perusahaan travel di kota Manado yaitu: Star Express, Virgo Tour and Travel, Nyiur Tour and Travel, Istana Tour and Travel, Forever Tour and Travel, dan Silk Air pada bulan November sampai Desember 2014 menggunakan metode analitik observasional dengan rancangan potong lintang.

Besar sampel penelitian ialah 30 subjek yang ditentukan dengan cara purposive sampling. Instrumen yang digunakan ialah kuesioner yang dapat menjelaskan maksud dan tujuan penelitian.

Data yang dikumpulkan meliputi umur, jenis kelamin, lama kerja di perusahaan, lama duduk per hari, posisi duduk, posisi lutut, posisi telapak kaki saat bekerja, bentuk kursi yang digunakan, dan intensitas nyeri. Data diolah dan dianalisis secara univariat untuk mendeskripsikan variabel penelitian yang disajikan dalam distribusi frekwensi dalam bentuk persentase dari tiap variabel dan analisis bivariat untuk mengetahui kaitan antara variabel bebas dan variabel terikat dengan menggunakan uji chi-square dan uji alternatif Fisher exact.

\section{HASIL PENELITIAN}

Tabel 1 memperlihatkan distribusi subjek penelitian berdasarkan umur. Dari 30 subjek penelitian yang terbanyak ialah yang berumur 20-25 tahun yaitu 21 subjek (70\%).

Tabel 2 menunjukkan distribusi subjek penelitian berdasarkan jenis kelamin. Dari 30 subjek penelitian terdapat 11 subjek penelitian (36,7\%) berjenis kelamin lakilaki dan 19 subjek penelitian (13,33\%) berjenis kelamin perempuan.

Tabel 3 memperlihatkan distribusi subjek penelitian berdasarkan lama kerja. Dari 30 subjek penelitian Yang terbanyak 
yaitu 21 subjek penelitian (70\%) dengan lama kerja 1-3 tahun.

Tabel 1. Distribusi Subjek Penelitian Berdasarkan Umur

\begin{tabular}{cccc}
\hline No & $\begin{array}{c}\text { Umur } \\
\text { (tahun) }\end{array}$ & $\mathrm{n}$ & $\%$ \\
\hline 1 & $20-25$ & 21 & 70 \\
2 & $26-30$ & 5 & 16,67 \\
3 & $31-35$ & 4 & 13,33 \\
& Jumlah & 30 & 100 \\
\hline
\end{tabular}

Tabel 2. Distribusi Subjek Penelitian berdasarkan Jenis Kelamin

\begin{tabular}{cccc}
\hline No & Jenis Kelamin & $\mathrm{n}$ & $\%$ \\
\hline 1 & Laki-laki & 11 & 36,7 \\
2 & Perempuan & 19 & 63,3 \\
& Jumlah & 30 & 100 \\
\hline
\end{tabular}

Tabel 3. Distribusi Subjek Penelitian Berdasarkan Lama Kerja

\begin{tabular}{cccc}
\hline No & Lama Kerja & $\mathrm{n}$ & $\%$ \\
\hline 1 & $1-3$ tahun & 21 & 70 \\
2 & $4-6$ tahun & 5 & 16,67 \\
3 & $7-9$ tahun & 4 & 13,33 \\
& Jumlah & 30 & 100 \\
\hline
\end{tabular}

Tabel 4 menunjukkan distribusi subjek penelitian menurut lama duduk. Subjek penelitian yang duduk selama 7-8 jam 21 orang (70\%) yang terbanyak.

Tabel 4. Distribusi Subjek Penelitian Menurut Lama Duduk

\begin{tabular}{cccc}
\hline No & $\begin{array}{c}\text { Lama Duduk } \\
\text { (jam) }\end{array}$ & $\mathrm{n}$ & $\%$ \\
1 & $1-2$ & 0 & 0 \\
2 & $3-4$ & 1 & 3,33 \\
3 & $5-6$ & 7 & 23,4 \\
4 & $7-8$ & 21 & 70 \\
5 & $9-10$ & 1 & 3,33 \\
& Jumlah & 30 & 100 \\
\hline
\end{tabular}

Tabel 5 menunjukkan distribusi subjek penelitian menurut LBP. Yang mengalami LBP sebanyak 27 orang (90\%) dan yang tidak mengalami LBP sebanyak 3 orang (10\%).
Tabel 5. Distribusi Subjek Penelitian Menurut LBP

\begin{tabular}{cccc}
\hline No & LBP & $\mathrm{n}$ & $\%$ \\
\hline 1 & Ya & 27 & 90 \\
2 & Tidak & 3 & 10 \\
& Jumlah & 30 & 100 \\
\hline
\end{tabular}

Tabel 6 memperlihatkan distribusi subjek penelitian menurut posisi duduk. Yang terbanyak ialah subjek penelitian yang duduk dengan posisi rileks yaitu 18 orang (60\%).

Tabel 6. Distribusi Subjek Penelitian Menurut Posisi Duduk

\begin{tabular}{cccc}
\hline No & Posisi Duduk & n & $\%$ \\
\hline 1 & Membungkuk & 7 & 23,33 \\
2 & Tegak & 5 & 16,67 \\
3 & Rileks & 18 & 60 \\
& Jumlah & 30 & 100 \\
\hline
\end{tabular}

Tabel 7 menunjukkan distribusi subjek penelitian berdasarkan posisi lutut. Yang terbnyak ialah 26 orang (86,67\%) dengan saat duduk posisi lututnya sejajar pinggul.

Tabel 7. Distribusi Subjek Penelitian Menurut Posisi Lutut

\begin{tabular}{cccc}
\hline No & Posisi Lutut & $\mathrm{n}$ & $\%$ \\
\hline 1 & Lebih tinggi dari & 3 & 10 \\
& pinggul & & \\
2 & Sejajar pinggul & 26 & 86,67 \\
3 & Lebih rendah dari & 1 & 3,33 \\
& $\begin{array}{c}\text { pinggul } \\
\text { Jumlah }\end{array}$ & 30 & 100 \\
\hline
\end{tabular}

Tabel 8 memperlihatkan distribusi subjek penelitian menurut posisi telapak kaki. Yang terbanyak ialah 27 subjek (90\%) duduk dengan telapak kaki pada posisi lutut fleksi $90^{\circ}$.

Tabel 8. Distribusi Subjek Penelitian Menurut Posisi Telapak Kaki

\begin{tabular}{cccc}
\hline No & Posisi Telapak Kaki & $\mathrm{n}$ & $\%$ \\
\hline 1 & $>90^{\circ}$ & 1 & 3,33 \\
2 & $90^{\circ}$ & 27 & 90 \\
3 & $<90^{\circ}$ & 2 & 6,67 \\
& Jumlah & 30 & 100 \\
\hline
\end{tabular}


Tabel 9 memperlihatkan distribusi subjek penelitian menurut bentuk kursi yang digunakan. Dari 30 subjek penelitian, yang terbanyak yaitu 15 orang (50\%) menggunakan kursi tipe I, diikuti 12 orang (40\%) kursi tipe III.

Tabel 9. Distribusi Subjek Penelitian Menurut Bentuk Kursi yang Digunakan

\begin{tabular}{cccc}
\hline No & Bentuk Kursi & $\mathrm{n}$ & $\%$ \\
\hline 1 & Tipe I & 15 & 50 \\
2 & Tipe II & 1 & 3,33 \\
3 & Tipe III & 12 & 40 \\
4 & Tipe IV & 1 & 3,33 \\
5 & Tipe V & 1 & 3,33 \\
& Jumlah & 30 & 100 \\
\hline
\end{tabular}

Tabel 10 memperlihatkan distribusi subjek penelitian menurut intensitas nyeri. Dari 30 subjek penelitian, 16 orang (53,33\%) mengalami LBP dengan intensitas nyeri skala 4-6 (sedang), 8 orang dengan intensitas nyeri skala 1-3 (ringan), 1 orang (3,33\%) dengan intensitas nyeri skala 7-9 (berat), sedangkan 3 orang (10\%) tidak mengalami nyeri.

Tabel 10. Distribusi Subjek Penelitian Menurut Intensitas Nyeri

\begin{tabular}{cccc}
\hline No & Intensitas Nyeri & n & $\%$ \\
\hline 1 & Skala 0 & 3 & 10 \\
2 & Skala 1-3 & 8 & 26,67 \\
3 & Skala 4-6 & 16 & 53,33 \\
4 & Skala 7-9 & 1 & 3,33 \\
5 & Skala 10 & 0 & 0 \\
& Jumlah & 30 & 100 \\
\hline
\end{tabular}

Tabel 11 memperlihatkan hubungan lama duduk dengan LBP. Hasil uji Fisher exact, nilai Sig 2 sided (p value) $=0,014$ dengan $\alpha<0,05$ maka dapat disimpulkan terdapat hubungan bermakna antara lama duduk dan LBP.

Tabel 11. Hubungan Lama Duduk dengan LBP

\begin{tabular}{|c|c|c|c|c|c|c|c|c|}
\hline \multirow{3}{*}{ Variabel } & \multirow{3}{*}{ Kategori } & \multicolumn{6}{|c|}{ Keluhan LBP } & \multirow{3}{*}{$\begin{array}{l}\text { Sig. } 2 \text { sided } \\
\text { (P value) }\end{array}$} \\
\hline & & \multicolumn{2}{|c|}{ Ya } & \multicolumn{2}{|c|}{ Tidak } & \multicolumn{2}{|c|}{ Total } & \\
\hline & & & $\%$ & $\mathrm{n}$ & $\%$ & $\mathrm{n}$ & $\%$ & \\
\hline \multirow[t]{5}{*}{ Lama Duduk } & $1-2$ jam & 0 & 0 & 0 & 0 & 0 & 0 & \multirow{5}{*}{0,014} \\
\hline & 3-4 jam & 0 & 0 & 1 & 3,33 & 1 & 3,33 & \\
\hline & 5-6 jam & 5 & 16,67 & 2 & 6,67 & 7 & 23,34 & \\
\hline & 7-9 jam & 21 & 70 & 0 & 0 & 21 & 70 & \\
\hline & $10 \mathrm{jam}$ & 1 & 3,33 & 0 & 0 & 1 & 3,33 & \\
\hline
\end{tabular}

Tabel 12 memperlihatkan hubungan umur, jenis kelamin, lama kerja, dan LBP. Hasil uji Fisher exact antara umur dan LBP, nilai Sig 2 sided ( $p$ value) $=0,605$ $>0,05$ maka dapat disimpulkan tidak terdapat hubungan bermakna antara umur dan LBP. Pada variabel jenis kelamin hasil uji Fisher exact antara jenis kelamin dan LBP, nilai Sig 2 sided (p value) $=0,702>$ 0,05 maka dapat disimpulkan tidak terdapat hubungan bermakna antara jenis kelamin dan LBP. Hasil uji Fisher exact antara lama kerja dan LBP, nilai Sig 2 sided (p value) $=0,490>0,05$ maka dapat disimpulkan tidak terdapat hubungan bermakna antara lama kerja dan LBP.

Tabel 13 memperlihatkan hubungan posisi duduk, posisi lutut, telapak kaki, dan bentuk kursi dengan LBP. Hasil uji Fisher exact antara posisi duduk dan LBP, nilai Sig 2 sided ( $\mathrm{p}$ value) $=0,028<0,05$ maka dapat disimpulkan terdapat hubungan bermakna antara posisi duduk dan LBP. Pada variabel posisi lutut, hasil uji Fisher exact antara posisi lutut dan LBP, nilai Sig 2 sided ( $p$ value) $=0,003<0,05$ maka dapat disimpulkan terdapat hubungan bermakna antara posisi lutut dan LBP. Hasil uji Fisher exact antara posisi telapak kaki dan LBP, nilai Sig 2 sided ( $\mathrm{p}$ value) $=0,145$ 
$>0,05$ maka dapat disimpulkan tidak terdapat hubungan bermakna antara posisi telapak kaki dan LBP. Hasil uji Fisher exact antara bentuk kursi dan LBP, nilai
Sig 2 sided $(\mathrm{p}$ value $)=0,968>0,05$ maka dapat disimpulkan tidak terdapat hubungan bermakna antara bentuk dan LBP.

Tabel 12. Hubungan Umur, Jenis Kelamin, dan Lama Kerja dengan LBP

\begin{tabular}{|c|c|c|c|c|c|c|c|c|}
\hline \multirow{3}{*}{ Variabel } & \multirow{3}{*}{ Kategori } & \multicolumn{4}{|c|}{ Keluhan LBP } & & & \multirow{3}{*}{$\begin{array}{l}\text { Sig. } 2 \text { sided } \\
\text { (P value) }\end{array}$} \\
\hline & & \multicolumn{2}{|c|}{ Ya } & \multicolumn{2}{|c|}{ Tidak } & \multicolumn{2}{|c|}{ Total } & \\
\hline & & $\mathrm{n}$ & $\%$ & $\mathrm{n}$ & $\%$ & $\bar{n}$ & $\%$ & \\
\hline \multirow[t]{3}{*}{ Umur } & 20-25 tahun & 19 & 63,33 & 2 & 6,67 & 21 & 70 & \multirow{3}{*}{0,605} \\
\hline & 26-30 tahun & 4 & 13,33 & 1 & 3,33 & 5 & 16,67 & \\
\hline & 31-35 tahun & 4 & 13,33 & 0 & 0 & 4 & 13,33 & \\
\hline \multirow[t]{2}{*}{ Jenis Kelamin } & Perempuan & 17 & 56,67 & 2 & 6,67 & 19 & 63,33 & \multirow[b]{2}{*}{0,702} \\
\hline & Laki- Laki & 10 & 33,33 & 1 & 3,33 & 11 & 36,67 & \\
\hline \multirow[t]{3}{*}{ Lama Kerja } & 1-3 tahun & 18 & 60 & 3 & 10 & 21 & 70 & \multirow{3}{*}{0,490} \\
\hline & 4-6 tahun & 5 & 16,67 & 0 & 0 & 5 & 16,67 & \\
\hline & 7-9 tahun & 4 & 13,33 & 0 & 0 & 4 & 13,33 & \\
\hline
\end{tabular}

Tabel 13. Hubungan Posisi Duduk, Posisi Lutut, Telapak Kaki, Bentuk Kursi, dengan LBP

\begin{tabular}{|c|c|c|c|c|c|c|c|c|}
\hline \multirow{3}{*}{ Variabel } & \multicolumn{7}{|c|}{ Keluhan LBP } & \multirow{3}{*}{$\begin{array}{l}\text { Sig. } 2 \text { sided } \\
\text { (P value) }\end{array}$} \\
\hline & \multirow{2}{*}{ Kategori } & \multicolumn{2}{|c|}{$\mathrm{Ya}$} & \multicolumn{2}{|c|}{ Tidak } & \multicolumn{2}{|c|}{ Total } & \\
\hline & & $\mathrm{n}$ & $\%$ & $\mathrm{n}$ & $\%$ & $\mathrm{n}$ & $\%$ & \\
\hline \multirow[t]{3}{*}{ Posisi Duduk } & Membungkuk & 6 & 20 & 1 & 3,33 & 7 & 23,33 & \\
\hline & Tegak & 18 & 60 & 0 & 0 & 18 & 60 & 0,028 \\
\hline & Rileks & 3 & 10 & 2 & 6,67 & 5 & 16,67 & \\
\hline \multirow[t]{3}{*}{ Posisi Lutut } & $\begin{array}{l}\text { Lebih tinggi dari } \\
\text { pinggul }\end{array}$ & 1 & 3,33 & 2 & 6,67 & 3 & 10 & \\
\hline & Sejajar pinggul & 25 & 83,33 & 1 & 3,33 & 26 & 86,67 & 0,003 \\
\hline & $\begin{array}{l}\text { Lebih rendah } \\
\text { dari pinggul }\end{array}$ & 1 & 3,33 & 0 & 0 & 1 & 3,33 & \\
\hline \multirow[t]{3}{*}{ Telapak Kaki } & $>90^{\circ}$ & 1 & 3,33 & 0 & 0 & 1 & 3,33 & \\
\hline & $90^{\circ}$ & 25 & 83,33 & 1 & 3,33 & 26 & 86,67 & 0,145 \\
\hline & $<90^{\circ}$ & 1 & 3,33 & 2 & 6,67 & 3 & 10 & \\
\hline \multirow[t]{5}{*}{ Bentuk Kursi } & Tipe I & 13 & 43,33 & 2 & 6,67 & 15 & 50 & \\
\hline & Tipe II & 1 & 3,33 & 0 & 0 & 1 & 3,33 & 0,968 \\
\hline & Tipe III & 11 & 36,67 & 1 & 3,33 & 12 & 40 & \\
\hline & Tipe IV & 1 & 3,33 & 0 & 0 & 1 & 3,33 & \\
\hline & Tipe V & 1 & 3,33 & 0 & 0 & 1 & 3,33 & \\
\hline
\end{tabular}

\section{BAHASAN}

Pada penelitian ini terdapat 35 subjek penelitian yang mengisi kuesioner namun hanya 30 orang yang memenuhi kriteria inkllusi. Jumlah subjek penelitian yang kurang memadai disebabkan karyawan perusahaan travel tidak terlalu banyak.

Pada penelitian ini umur subjek penelitian dibatasi 20-35 tahun. Umumnya keluhan otot skeletal mulai dirasakan pada usia kerja, yaitu 20-35 tahun. Keluhan pertama biasanya dirasakan pada usia 20 
tahun dan keluhan meningkat sejalan dengan bertambahnya umur. ${ }^{8}$

Data jenis kelamin yang didapat tidak berimbang. Dari total 30 subjek penelitian sebanyak 19 subjek penelitian perempuan $(63,5 \%)$ sementara subjek penelitian lakilaki yang hanya berjumlah 11 orang (36,7\%). Laki-laki dan perempuan berisiko yang sama terhadap keluhan LBP terutama pada usia produktif. ${ }^{9}$ Perusahaan travel banyak mempekerjakan karyawan perempuan daripada laki-laki.

Data lama kerja paling banyak pada kelompok yang bekerja 1-3 tahun di perusahaan travel yaitu sebanyak 21 subjek penelitian. Pada penelitian yang dilakukan Amelia at al. tentang hubungan masa kerja dengan LBP pada pekerja pembersih kulit bawang didapatkan bahwa masa kerja lebih dari 10 tahun memengaruhi terjadinya LBP. $^{10}$

Dalam penelitian ini dapat diketahui bahwa 1 subjek $(3,3 \%)$ yang duduk selama 3-4 jam, 7 subjek (23,4 \%) duduk selama 56 jam, 21 subjek (70\%) duduk selama 7-8 jam, dan 1 subjek (3,33\%) duduk selama 9-10 jam. Penelitian Rahmat (2009) menunjukkan prevalensi LBP pada pekerja yang duduk mencapai $60 \%$ dari pekerja. Kemampuan maksimal seseorang bekerja seharinya 8-10 jam; bila melebihi durasi waktu tersebut maka efisiensi dan kualitas kerja sangat menurun. ${ }^{11}$

Pada Tabel 5 distribusi subjek penelitian menurut LBP dapat diketahui bahwa subjek penelitian yang mengalami LBP sebanyak 27 orang (90\%) dan yang tidak mengalami LBP sebanyak 3 orang (10\%). Penelitian yang dilakukan oleh Sumekar menunjuk-kan bahwa LBP pada operator komputer di Lampung sebanyak 38 subjek penelitian (49,4\%). Sebagian besar subjek penelitian mengeluhkan adanya penjalaran nyeri baik di tungkai, bokong maupun leher. ${ }^{4}$

Dalam penelitian ini dapat diketahui bahwa subjek penelitian yang duduk dengan posisi membungkuk sebanyak 7 orang (23,33\%), posisi tegak 5 orang (16,67\%) dan posisi rileks 18 orang (60\%). Duduk dalam posisi yang baik (rileks) sangat penting sebab jaringan pada tulang belakang terhubung dengan ligamen dapat memicu rasa sakit jika posisi tidak tepat. Duduk membungkuk dapat meningkatkan aktifitas otot $>25 \%$ dari berat badan sedangkan duduk tegak aktifitas ototnya sama dengan $25 \%$ berat badan. Duduk rileks dapat mengurangi kejadian LBP pada operator komputer. Nyeri lebih sering terjadi pada posisi tegak dan membungkuk karena pada posisi ini otot-otot erektor spina lebih sering berkontraksi sehingga lebih cepat terjadi ketegangan yang berlebihan.

Data penelitian ini menunjukkan bahwa posisi lutut operator komputer yang mengalami LBP pada saat bekerja yang sejajar dengan pinggul sebanyak 26 orang (86,67\%). Tiga subjek penelitian (10\%) posisi lututnya lebih tinggi dari pinggul dan 1 subjek penelitian (3,33\%) posisi lutunya lebih rendah dari pinggul. Posisi lutut yang baik pada saat mengoperasikan komputer ialah lutut tetap setinggi pinggul dan sebaiknya kedua kaki tidak menyilang.

Distribusi subjek penelitian menurut posisi telapak kaki menunjukkan dari 30 subjek penelitian 27 subjek penelitian (90\%) duduk dengan telapak kaki pada posisi lutut fleksi $90^{\circ}$, dua subjek penelitian telapak kaki pada posisi lutut $<90^{\circ}$ dan satu subjek penelitian dudu dengan telapak kaki pada posisi lutut $>90^{\circ}$. Telapak kaki saat mengoperasikan komputer sebaiknya tidak menggantung (sudut lutut $>90^{\circ}$ ) namun menapak sempurna dimana sudut lutut fleksi $90^{\circ}$. Kursi yang tingginya tidak sesuai dapat menyebabkan telapak kaki dapat menggantung. Sebaiknya disediakan pijakan kaki yang sesuai agar kaki dapat menapak dengan bagus.

Bentuk kursi yang paling sering digunakan pada perusahaan travel tempat dilakukan penelitian ialah kursi beroda dengan sandaran punggung dan tanpa sandaran tangan. Kursi yang tanpa sandaran tangan akan membuat ketika operator istirahat akan cenderung meletakkan tangannya ke atas meja dengan posisi badan membungkuk kedepan. Hal ini dapat memperburuk risiko LBP. Kursi 
dengan sandaran punggung tanpa sandaran tangan dan tidak beroda juga memperburuk LBP karena tidak memudahkan operator komputer untuk leluasa bergerak (immobile).

Distribusi subjek penelitian menurut intensitas nyeri (Tabel 10) memperlihatkan bahwa yang terbanyak yaitu 16 orang (53,33\%) mengalami LBP dengan intensitas nyeri skala 4-6 (sedang) sedangkan subyek lainnya bervariasi dari intensitas nyeri skala 1-3 (ringan) dan intensitas nyeri skala 7-9 atau berat. Juga terdapat subjek penelitian yang sama sekali tidak mengalami nyeri. Untuk subjek penelitian dengan nyeri bersifat ringan disarankan untuk melakukan tindakan pencegahan atau mengurangi risiko LBP dengan berolahraga sebelum memulai aktifitas kerja, dan juga mengistirahatkan badan di sela jam kerja bila memungkinkan agar otot dapat berelaksasi. Untuk subjek penelitian dengan nyeri bersifat sedang dan berat sebaiknya segera memeriksakan diri ke dokter agar keluhan tidak bertambah parah.

Penelitian ini menunjukkan bahwa terdapat hubungan antara lama duduk dan keluhan LBP pada operator komputer perusahaan travel. Hasil ini didasarkan pada hasil uji Fisher exact test dengan nilai $\mathrm{p}=0,014(<0,05)$. Sejumlah penelitian menunjukkan keterkaitan antara duduk lama dengan LBP. Magora menemukan prevalensi LBP sebesar 12,6\% pada orang yang sering bekerja duduk selama $>4$ jam. Penelitian pada murid sekolah di Skandinavia oleh Tousler menunjukkan 41,6\% yang menderita LBP selama duduk di kelas, terdiri dari $30 \%$ yang duduk selama 1 jam dan $70 \%$ setelah duduk $>1$ jam. Penelitian oleh Emami menunjukkan LBP berkaitan dengan duduk lama $>4$ jam ( $<<0,05)$. Pada penelitian ini diperoleh hasil uji Fisher exact, nilai Sig 2 sided $\mathrm{p}=$ $0,014<0,05$ maka dapat disimpulkan bahwa terdapat hubungan bermakna antara lama duduk dan LBP.

\section{SIMPULAN}

Dari hasil penelitian dapat disimpulkan bahwa terdapat hubungan bermakna antara lama duduk dengan LBP pada operator komputer perusahan traverel di Manado.

Hasil Numeric Rating Scale (NRS) menunjukkan bahwa nyeri LBP yang terbanyak pada operator komputer ialah nyeri bersifat sedang (derajat nyeri 4-6).

\section{SARAN}

Perlu diadakan penelitian tentang lama duduk dengan jenis pekerjaan berbeda juga dengan jumlah sampel yang lebih besar.

Penelitian selanjutnya diharapkan dapat menggunakan metode penelitian kasus-kontrol.

Operator Komputer perusahaan travel kiranya memperhatikan cara duduk yang benar yaitu duduk dengan posisi rileks saat bekerja, posisi lutut fleksi $90^{\circ}$ sejajar pinggul, dan tidak menyilangkan kaki untuk mengurangi resiko terjadinya LBP. Beristirahat di antara jam kerja untuk meregangkan otot-otot yang tegang sebagai upaya pencegahan LBP dan memeriksakan diri ke dokter bila sakit berlanjut.

\section{DAFTAR PUSTAKA}

1. Hoy D, Brooks P, Blyth F, Buchbinder R. The Epidemiology of Low Back Pain. Best Practice \& Research Clinical Rheumatology. 2010;24:77.

2. Munir S. Analisis Nyeri Punggung Bawah Pekerja Bagian Final Packing dan Part Supply di PT.X Tahun 2012 [Tesis]. Jakarta: Universitas Indonesia, 2012.

3. Wulandari RA, Maja PS, Khosama $H$. Gambaran faktor yang mempengaruhi nyeri punggung bawah pada buruh kapal. eCliniC. 2014;2(1).

4. Dyah RW, Natalia D. Nyeri Punggung pada Operator Komputer Akibat Posisi dan Lama Duduk. MKB. 2010;42:124.

5. Ehrlich GE. Low Back Pain. Bulletin Of The World Health Organization. 2003;81:672.

6. Rahmawati LDA. Hubungan Sikap Kerja Duduk Dengan Keluhan Nyeri Punggung Bawah Pada Pekerja Rental Komputer di Pabelan Surakarta [KTIS]. Surakarta: Universitas Muhammadiyah, 2008. 
Sari, Mogi, Angliadi: Hubungan lama duduk dengan kejadian low back pain ...

7. Pirade A. Hubungan Posisi dan Lama Duduk Dengan Kejadian Nyeri Punggung Bawah (NPB) Mekanik Kronik Pada Karyawan Bank. Jurnal Biomedik Supl, 2012.

8. Huldani. Nyeri Punggung [Refarat]. Banjarmasin: Universitas Lambung Mangkurat, 2012.

9. Fatimah T. Faktor yang berhubungan dengan nyeri punggung bawah pada karyawan bagian penjahitan PT. Intigarmindo Persada Jakarta. 2010. [cited 2014 Sep 23] Available from: https://library.upnvj.ac.id.

10. Putri AS. Hubungan Masa Kerja dan Posisi Kerja dengan Kejadian Low Back Pain Pada Pekerja Pembersih Kulit Bawang di Unit Dagang (UD) Bawang Lanang Kelurahan Iringmulyo Kota Metro, 2014.

11. N. C. Deparment of Labor. A guide to ergonomics, 2009. 